\title{
Caminhos Trilhados Com A Educação Ambiental Nas Cátedras, Centro e Instituto Paulo Freire no Brasil: Analisando as Concepções dos Dirigentes
}

Paths Followed With Environmental Education In The Paulo Freire

Chairs, Center And Institute In Brazil: Analyzing The Leaders'

Conceptions

Caminos Seguidos Com Educación Ambiental Em Las Cátedras, El Centro Y El Instituto Paulo Freire En Brasil: Analizando Las Concepciones De Los Líderes

MARCOS PAULO DA SILVA SANTANA ${ }^{1}$, RAYANNE FERNANDA DA COSTA MELO², MONICA LOPES FOLENA ARAÚJO3

${ }^{1}$ Universidade Federal Rural de Pernambuco - UFRPE

2 Universidade Federal Rural de Pernambuco - UFRPE

${ }^{3}$ Universidade Federal Rural de Pernambuco - UFRPE

\begin{abstract}
RESUMO: A Educação Ambiental (E A) pode ser considerada uma dimensão para que os individuos desenvolvam habilidades e atitudes sustentáveis através de uma consciência crítica. Tendo em vista a aproximação da EA com os pensamentos e a metodologia freireana torna-se importante investigar a influência de Paulo Freire para trabalhos com essa temática. Desse modo, o objetivo deste trabalho é compreender as concepções dos dirigentes de instituições freireanas sobre a $\mathrm{E} A$ nestes espaços formativos. Recorremos à entrevista como instrumento de coleta de dados. As entrevistas foram gravadas em ándio e transcritas. A análise dos dados foi feita à luz da análise de conteúdo (BARDIN, 1994). Os resultados encontrados nos permitem inferir que, na concepção dos dirigentes, a $\mathrm{E} A$ se relaciona diretamente com as ideias de Freire e são várias as ações desenvolvidas com $\mathrm{E} A$ nestes espaços.
\end{abstract}

EDUCAÇÃO AMBIENTAL. ESPAÇOS FORMATIVOS. PAULO FREIRE. PEDAGOGIA FREIREANA. SUSTENTABILIDADE.

\begin{abstract}
Environmental Education (EE) can be considered a dimension for individualst o develop sustainable skills and attitudest hrough critical awareness. In view oft he approach of EE with Freire's thoughts and methodology, it is important to investigate the influence of Paulo Freire for works with this theme. In this way, the objective of this work is to understand the conceptions of the leaders of Freiriani nstitutions about EE in these formative spaces. We used the interview as a data collection instrument. The interviews were audio recorded and transcribed. Data analysis was performed in the light of content analysis (BARDIN, 1994). The results found allow us to infer that in the directors' conception, EE is directly related to Freire's ideas, and there are several actions developed with EA in these spaces.
\end{abstract}

Os autores cedem à Revista Internacional Educon os direitos de primeira publicaşão do presente artigo. Aplicam-se os termos de uma licença Creative Commons Atribuição 4.0 Internacional (CC BY 4.0), que permite o uso irrestrito, a distribuição e a reprodução em qualquer meio desde que a publicação original seja corretamente citada. 


\title{
ENVIRONMENTAL EDUCATION. FORMATIVE SPACES. PAULO FREIRE. FREIRE'S PEDAGOGY. SUSTAINABILITY.
}

\begin{abstract}
RESUMEN:La Educación Ambiental (EA) puede considerarse una dimensión para que las personas desarrollen habilidades y actitudes sostenibles a través de la conciencia crítica. En vista de La aproximación de EA com los pensamientos y La metodología de Freire, es importante investigar La influencia de Paulo Freire para lostrabajoscon este tema. De esta manera, el objetivo de este trabajo es comprender lãs concepciones de los líderes de lãs instituciones freirianas sobre la EA em estos espacios formativos. Utilizamos la entrevista como instrumento de recolección de datos. Las entrevistas fueron grabadas en audio y transcritas. El análisis de datos se realizó a la luz de Lanálisis de contenido (BARDIN, 1994). Los resultados encontrados nos permiten inferir que, em la concepción de los directores, EA está directamente relacionada com lãs ideas de Freire, y hay varias acciones desarrolladas con $E A$ en estos espacios.

EDUCACIÓN AMBIENTAL. ESPACIOS FORMATIVOS. PAULO FREIRE. PEDAGOGÍA DE FREIRE. SUSTENTABILIDAD.
\end{abstract}

\section{Introdução}

A Constituição da República do Brasil no Artigo 225, afirma como direito inerente ao homem um "meio ambiente ecologicamente equilibrado", conforme podemos verificar no trecho a seguir: "Todos têm direito ao meio ambiente ecologicamente equilibrado, bem de uso comum do povo e essencial à sadia qualidade de vida, impondo-se ao Poder Público e à coletividade o dever de defendê-lo e preservá-lo para as presentes e as futuras gerações" (BRASIL, 1988).

Entretanto, vivemos em um dilema em que decidimos se utilizamos o meio natural como mercadoria, para fins capitalistas, ou se o reconhecemos como patrimônio da humanidade, fundamental para a manutenção da vida. Sendo assim:

\begin{abstract}
A educação ambiental, numa perspectiva crítica, não pode abrir mão do rigor teóricometodológico na análise da realidade. O pensamento crítico, ao desvendar o modo de produção capitalista, sua estrutura interna, as contradições que engendra enquanto processo social, seus limites materiais, aponta também os mecanismos de ocultamento dessa realidade, elaborados pela ideologia dominante. É importante compreender os traços fundamentais de um sistema que se baseia na exclusão social, na exploração da classe trabalhadora, na destruição da natureza e na mercantilização de todos os elementos da natureza e das dimensões sociais e culturais das relações humanas (TREIN, 2008, p. 43).
\end{abstract}

Podemos perceber a Educação Ambiental (EA) como uma dimensão que pode ser utilizada para que os indivíduos possam construir valores, conhecimentos e habilidades para serem agentes transformadores a partir de ações que levem à conservação do meio ambiente e à sustentabilidade. É por isto que a EA deveria ser considerada "um componente essencial e permanente da educação nacional, devendo estar presente, de forma articulada, em todos os níveis e modalidades do processo educativo, em caráter formal e não-formal" (Art. $1^{\circ}$ da Lei ${ }^{\circ}$ 9.795/99).

O processo educativo, por sua vez, deve procurar sensibilizar os estudantes para as questões ambientais e sociais através do desenvolvimento de estratégias, a partir das quais os 
estudantes obtêm informações relevantes e constroem conhecimento de maneira significativa, contribuindo para o desenvolvimento de uma consciência crítica para que se possam enfrentar problemas socioambientais.

A respeito das problemáticas envolvendo o meio ambiente, Maldonado (1971), diz que as mesmas podem ser consideradas mais uma crise de sociedade do que da natureza. Nesse sentido, a EA não tem em vista apenas questões ambientais voltadas para o meio natural ou selvagem, mas abrange questões éticas e políticas da sociedade que estamos inseridos, isto porque "O mundo natural e o mundo social se auto influenciam, sendo impossível dissociálos" (ARAÚJO, 2015, p. 210). Ventura e Souza (2010), afirmam que a EA surgiu visando enfrentar a crescente crise ambiental, articulando as dimensões sociais e ambientais.

Logo, percebemos que a EA tem como característica e, por isto, possibilidade, a transformação e a humanização, pois permite que os indivíduos reflitam sobre a sua relação com a natureza e o ambiente. Sobre isso, Carvalho (2006), afirma que a EA fomenta sensibilidades afetivas e capacidades cognitivas para uma nova leitura de mundo. Sato (2003), por sua vez, entende que essa sensibilização propiciada pela EA é muito importante para a mudança de atitudes socioambientais, e Araújo (2015, p. 209) afirma que "é criando, recriando e decidindo que o ser humano dinamiza o mundo socioambiental, em um processo que Paulo Freire chama de Integração". Apenas integrado ao mundo, desenvolvendo o sentimento de pertencimento e a criticidade é que o humano pode ter compreensões e atitudes modificadas positivamente.

Para Trein (2008), a EA pode contribuir para ampliar uma visão crítica da sociedade e, com isso, incentivar uma maior participação dos brasileiros nas discussões sobre as políticas públicas e os movimentos sociais que estão voltados para a resolução de problemas ambientais. Araújo (2015, p, 146) atesta: “[...] A discussão e a análise dessas questões contribuem para a formação de um sujeito humanizado e crítico - sujeito consciente da realidade ambiental e social, da indissociabilidade entre essas duas condições de ser transformador, que pode nelas intervir". Neste contexto, o diálogo assume um lugar de destaque para a construção da humanização e criticidade, pois permite ver as questões socioambientais na perspectiva da práxis social, que é o compromisso entre a reflexão, que permite pensar a relação entre a sociedade e o mundo e a prática transformadora (Ibid., p.148).

Entretanto, "torna-se necessário situar o ambiente conceitual e político onde a educação ambiental pode buscar sua fundamentação enquanto projeto educativo que pretende transformar a sociedade" (CARVALHO, 2006, p. 18). Para tal, devemos fugir de uma educação ambiental nos moldes da "educação bancária" na qual "sua prática educativa, reproduz os paradigmas da sociedade moderna, dentre eles o cientificismo, cartesianismo e o antropocentrismo que resulta numa relação desintegrada entre sociedade e natureza" (PIEPER; SANTOS; PIMENTEL, 2012, p. 697). Ou seja, devemos buscar uma EA crítica transformadora emancipatória que:

[...] Estimula o pensar autêntico e emancipado que não deixa confundir por visões parciais da realidade. Assim, deve inspirar-se em ações educativas que posicionem a educação imersa no mundo da vida, historicizada e espacialmente situada, conectada às questões urgentes do nosso tempo, que acrescenta uma especificidade de compreender as relações sociedade-natureza, em um processo de formação de sujeitos emancipados, autores da própria história, buscando religar o conhecimento do mundo à vida dos educandos para torná-los leitores críticos do seu mundo à intervenção nos problemas e conflitos ambientais (Ibid., p. 697-698). 
Essa concepção do poder da educação humanizadora, crítica, emancipatória e transformadora aproxima-se do pensamento freireano. Em suas obras, Paulo Freire dialoga sobre a educação como agente da transformação e na indissociabilidade do meio social com o meio ambiental.

Lima (2004) nos fala que a educação é um importante instrumento de mudança social que pode contribuir positivamente para alterações sociais e culturais de uma sociedade, porém ela tem seus limites, pois não possui o poder de resolver todos os problemas que se apresentam, nem de realizar transformações com a amplitude e a profundidade que muitas vezes são esperadas. Por outro lado, “[...] Pode estimular as sensibilidades, despertar consciências e exercitar ações libertadoras, humanizadoras e cidadãs capazes de promover a vida e as relações dos indivíduos consigo mesmos, com os seus semelhantes em sociedade e com o meio ambiente" (Ibid., p. 111-112).

A metodologia utilizada por Paulo Freire para a alfabetização de adultos e as suas obras são altamente difundidas em todo o mundo e "a educação de Paulo Freire vem sendo campo de estudo realizado por pesquisadores em Grupos de Pesquisas, Centros de Investigações, Institutos e Cátedras Paulo Freire, instituídos em diversos países na América Latina entre outros" (OLIVEIRA; SANTOS, 2018). No Brasil, temos 08 (oito) Cátedras, 01 (um) Instituto e 01 (um) Centro Paulo Freire. As Cátedras estão distribuídas em quatro regiões: Norte, Nordeste, Sul e Sudeste. Sendo a mais recente a Cátedra Paulo Freire: Educação para Sustentabilidade, inaugurada no dia 20 de setembro de 2018 na Universidade Federal Rural de Pernambuco (UFRPE), em Recife - PE.

O Instituto Paulo Freire (IPF) nasceu da ideia do próprio Paulo Freire (1921-1997), a partir do seu desejo de reunir pessoas e instituições para que pudessem refletir e melhorar as suas práticas sobre a educação humanizadora e transformadora, o IPF tem como objetivo dar continuidade ao legado de Paulo Freire "educar para transformar", e promover uma educação emancipadora, combater a injustiça, discriminação, violência, preconceito e exclusão (Instituto Paulo Freire).

Já o Centro Paulo Freire - Estudos e Pesquisas "foi criado pelas mãos de um grupo de professores/as de instituições diversas" (SANTIAGO; BATISTA NETO; GUEDES, 2016, p. 151), e iniciou suas atividades no ano de 1998. Seu objetivo é "promover, estimular e divulgar a realização de estudos, pesquisas, cursos, inovações pedagógicas e seminários sobre a educação brasileira, particularmente, quanto às implicações políticas e sociais" (JORNAL UTOPIA, 2000). A sede do Centro Paulo Freire está localizada no Centro de Educação no Campus da Universidade Federal de Pernambuco (UFPE).

Segundo Santiago, Batista Neto e Guedes (2016), a presença de Paulo Freire é evidenciada através do seu legado onde há uma práxis político-educativa com o ensino, pesquisa e extensão e com o reconhecimento da contribuição do educador brasileiro e planetário.

Tendo em vista a aproximação da EA com os pensamentos e a metodologia freireana, torna-se importante investigar quais as concepções sobre a EA dos dirigentes de Cátedras, Centro e Instituto Paulo Freire e quais as ações que vêm sendo desenvolvidas com a EA nesses espaços formativos.

Diante desse contexto, o presente trabalho tem por objetivo geral compreender as concepções dos dirigentes das Cátedras, Centro e Instituto Paulo Freire sobre a EA nestes espaços formativos. Para alcançá-lo, delineamos como objetivos específicos: analisar a influência de Paulo Freire para trabalhos com EA na visão dos dirigentes desses espaços; 
identificar as ações ali desenvolvidas, que envolvam a EA; e mapear contribuições das ações desenvolvidas com a EA.

\section{Metodologia}

Os atores sociais da presente pesquisa são dirigentes das Cátedras, Centro e Instituto Paulo Freire. Os mesmos foram contatados por email ou telefone e, após esclarecimentos em relação à pesquisa, foi agendado local e hora para a entrevista quando foi solicitado aos mesmos que assinassem um Termo de Consentimento Livre e Esclarecido (TCLE) para que suas falas pudessem ser explicitadas na pesquisa sem identificação dos mesmos.

Recorremos à entrevista para a coleta de dados, afinal a mesma é considerada uma das modalidades de interação entre duas ou mais pessoas com um propósito diferente da mera conversação, pois nela se valoriza o uso da palavra, símbolo e signo, devido ao seu valor para as relações comunicativas (FRASER; GONDIM, 2004). Ainda conforme Gil (2008, p. 117, destaque do autor):

\footnotetext{
É fácil verificar como, entre todas as técnicas de interrogação, a entrevista é a que apresenta maior flexibilidade. Tanto é que pode assumir as mais diversas formas. Pode caracterizar-se como informal, quando se distingue da simples conversação apenas por ter como objetivo básico a coleta de dados. Pode ser focalizada quando, embora livre, enfoca tema bem específico, cabendo ao entrevistador esforçar-se para que o entrevistado retorne ao assunto após alguma digressão. Pode ser parcialmente estruturada, quando é guiada por relação de pontos de interesse que o entrevistador vai explorando ao longo de seu curso. Pode ser, enfim, totalmente estruturada quando se desenvolve a partir de relação fixa de perguntas. Nesse caso, a entrevista confunde-se com o formulário.
}

Nesse sentido, utilizamos roteiro de entrevista composto por questões norteadoras, passíveis de serem acrescidas outras perguntas a depender da resposta apresentada pelo(a) entrevistado(a), de modo a alcançarmos os objetivos específicos delineados no presente trabalho. São elas:

1. Qual é a sua concepção em relação à influência de Paulo Freire para trabalhos com a Educação Ambiental?

2. A Cátedra/Instituto desenvolve ações que envolvam Educação Ambiental?

3. (caso afirmativo) Que ações são desenvolvidas? Com que periodicidade? Você poderia citar contribuições dessas ações?

4. (caso negativo) Por que não são desenvolvidas atividades que envolvam Educação Ambiental?

As entrevistas foram gravadas em áudio e transcritas, pois, como sugere Schraiber (1995), o uso de gravador possibilita a ampliação da captação de elementos de comunicação de extrema importância, tais como pausas de reflexão, dúvidas ou entonação da voz, aprimorando assim a compreensão da narrativa que pretendíamos analisar. Como nos orientam Belei et al. (2008), para realizar a análise realizamos a transcrição das entrevistas na íntegra, inclusive atentando para os comportamentos não-verbais, a entonação da voz e possíveis gestos que registramos. 
A análise foi feita seguindo as orientações de Bardin (1994). No que diz respeito à análise de conteúdo, a autora afirma que a análise consiste, de modo geral, na decomposição dos discursos e identificação de categorias comuns, levando em consideração o contexto que a pesquisa está inserida. A análise de conteúdo é dividida em três momentos: pré-análise, exploração do material e tratamento de dados. A primeira etapa (pré-análise) consiste na organização do material; a segunda etapa é o momento de aprofundamento orientado pelas hipóteses; e o terceiro e último momento é o tratamento dos dados, ou seja, a análise propriamente dita.

Para garantir o anonimato dos participantes da pesquisa, identificamos os mesmos pela letra " $\mathrm{D}$ " de "dirigente" e um número. No total, foram entrevistados o dirigente do Instituto Paulo Freire, o do Centro Paulo Freire e dirigentes das Cátedras Paulo Freire localizadas nas regiões Norte (1), Nordeste (2), Sul (1) e Sudeste (2) e um ex-dirigente, pois este foi indicado pela atual gestão para ser entrevistado por ter sido o fundador da Cátedra. Os demais atores sociais serão entrevistados posteriormente.

\section{Resultados e Discussão}

Através das respostas obtidas pudemos perceber as concepções sobre a educação ambiental nesses espaços formativos, a influência de Paulo Freire para trabalhos sobre EA e quais as ações que estão sendo desenvolvidas envolvendo a educação ambiental. Vale salientar que a quarta questão não foi respondida por nenhum entrevistado, pois os dirigentes entrevistados até o momento informaram que atividades envolvendo a EA são desenvolvidas nos referidos espaços.

Nos itens seguintes apresentamos as respostas detalhadas dos dirigentes.

\subsection{Influência de Paulo Freire para trabalhos com a Educação Ambiental}

Inicialmente, D1 afirma que "a contribuição de Paulo Freire é muito vasta e o seu pensamento sem fronteiras", aponta também que "são os campos de conhecimento que buscam em Paulo Freire a contribuição e não Paulo Freire que define o lugar da sua compreensão". A respeito das contribuições de Freire para a comunidade científica, pesquisas realizadas pela Rede Freireana de Pesquisadores (RFP) reafirmam que a mesma se dá em diversos campos e áreas do conhecimento científico (SAUL, 2012, 2016). Sobre as contribuições específicas de Freire para a EA, Torres e Delizoicov (2009) certificam que os trabalhos que fazem essa aproximação vêm aumentando com o passar do tempo nos ambientes formais.

Saul (2016, p. 12) destaca que a atualidade do pensamento freireano é facilmente verificável devido à "multiplicidade de trabalhos teórico-práticos que se desenvolvem, tomando o seu pensamento e a sua prática como referências, em diferentes áreas do conhecimento, ao redor do mundo". Cortella corrobora com esse pensamento ao afirmar que Paulo Freire "é um clássico porque o seu trabalho não perdeu vitalidade, não perdeu irrigação, conexão com a vida e com o sangue que a vida partilha e emana" (2001, p. 11). O quefazer de Paulo Freire tem inspirado várias redes de ensino no Brasil, que são comprometidas com a 
educação crítico-emancipadora (SAUL, 2012, 2016; SILVA, 2015). Segundo Araújo (2015), o quefazer é um termo criado e estudado por Paulo Freire, que expressa a indissociabilidade da teoria da prática que se torna concreta por seres reflexão-ação.

D1 destaca ainda a perspectiva relacional, como podemos observar em sua fala:

[...] A contribuição de Paulo Freire está desde o momento que a gente começa a pensar quem é este sujeito, quem é este ser humano, quem é o homem, quem é a mulher, independente do seu tamanho, da sua idade, da sua escolarização, qual é a relação deste ser com o mundo [...].

A fala de D1 evidencia, entre outras coisas, uma característica do ser humano apontada por Freire, que nos identifica como "seres de relações" (FREIRE, 1996; FREIRE; FAUNDEZ, 2002). Destacamos ainda que, para Freire (1989, p. 39-40) "há uma pluralidade de relações do homem com o mundo, na medida em que responde à ampla variedade dos seus desafios".

Em relação ao termo "mundo", para Freire ele tem diversos sentidos, tendo em vista que, em alguns momentos se refere à realidade, ou à natureza, ou até mesmo ao sistema. Dessa forma, "o polo mundo passa a ser tomado em seu sentido de realidade social, espaço histórico e, portanto, contraditório, mutável. É o mundo da opressão de classe e de múltiplas contradições" (CALADO, 2001, p. 20). Em Educação como Prática de Liberdade, Freire nos esclarece que:

[...] As relações que o homem trava no mundo com o mundo (pessoais, impessoais, corpóreas e incorpóreas) apresentam uma ordem tal de características que as distinguem totalmente dos puros contatos, típicos da outra esfera animal. Entendemos que, para o homem, o mundo é uma realidade objetiva, independente dele, possível de ser conhecida. É fundamental, contudo, partirmos de que o homem, ser de relações e não só de contatos, não apenas está no mundo, mas com o mundo. Estar com o mundo resulta de sua abertura à realidade, que o faz ser o ente de relações que é (FREIRE, 1989, p. 39).

D1 segue afirmando que, a partir do momento que começamos a tomar como base os pensamentos de Freire "devemos pensar nessa perspectiva relacional na dimensão cultural" (D1). Pois, a mesma considera que:

[...] em Paulo Freire, cultura são os processos de vida das pessoas, o modo como as pessoas gerenciam e garantem a sua vida, a sua sobrevivência. Então, ao pensar nisto ou a partir disto, a gente já tem a grande contribuição de Paulo Freire.

Logo, "não é uma contribuição de método, não é a compreensão de um princípio, mas os princípios nascem dessa visão mais ampla da consecução" (D1).

Para Dickmann e Carneiro "Esta é uma das grandes contribuições freireanas, a pertença do ser humano ao mundo-natureza como unidade interdependente, superando uma visão dicotômica" e reafirma a indissociabilidade entre sociedade e natureza (2012, p.92).

D1 reitera que:

[...] A pedagogia Paulo Freire ou pensamento Paulo Freire é um pensamento ou é uma pedagogia do ser humano. Logicamente que ao dar uma contribuição para o pensar, viver, trabalhar, se relacionar com o ser humano é uma contribuição para a educação ambiental [...]. 
D2 declara que:

Paulo Freire é um referencial teórico necessário para quem pesquisa e debate a educação ambiental, porque o seu olhar é ético-político, para todos aqueles e aquelas que sofrem qualquer tipo de violência e de opressão social.

Diante das respostas obtidas, destacamos a fala de Saul (2016, p. 13) sobre a indignação na vida e obra de Paulo Freire:

A vida e a obra de Paulo Freire revelam a sua indignação contra as injustiças sociais que negam a humanização. Desde os seus primeiros escritos esse tema esteve presente, engendrando a utopia de sua proposta político-pedagógica.

Para Freire, faz parte do pensar certo rejeitar qualquer tipo de discriminação. Seja ela racial, de classe ou de gênero, pois a prática preconceituosa nega a democracia aos indivíduos (FREIRE, 1996).

$\mathrm{Na}$ perspectiva freireana, através de uma educação emancipatória, crítica e humanizadora, o sujeito pode transformar o mundo. Para tanto, é necessária a conscientização para a compreensão da realidade "para o homem assumir seus compromissos, como ser histórico, torna-se necessário que o mesmo se conscientize" (ARAÚJO, 2012, p. 75). Portanto, Paulo Freire acreditava que através da conscientização o homem tem o potencial para ser mais, caracterizado como um "processo que permite aos indivíduos serem compreendidos e compreenderem-se como ser inteiro, complexo, dotado de uma condição múltipla cognitiva, emocional e espiritual" (LEITÃO, 2015, p. 33). Em suma, o "sujeito que tem a possibilidade de conhecer e intervir na realidade, transformando-a" (SANTIAGO; BATISTA NETO; GUEDES, 2016, p. 159).

Neste sentido D3 acredita que a influência de Paulo Freire se dá "sobretudo a partir dos conceitos como conscientização e humanização”. E segue afirmando:

Eu penso que a EA requer colocar em prática o exercício desses conceitos da conscientização e da humanização que são conceitos tão importantes durante toda a obra, e de toda a trajetória de Paulo Freire.

Para Freire "quanto mais conscientizados nos tornamos, mais capacitados estamos para sermos anunciadores e denunciadores, graças ao compromisso de transformação que assumimos" (1980, p. 28).

D4 corrobora ao falar que Paulo Freire colabora com ações socioambientais quando “está falando da constituição do ser coletivo, está pensando também na libertação das situações de opressão. Entendendo por essa libertação de opressão muitas vezes dentro de nós mesmos". Para Freire, a Pedagogia do oprimido é "a pedagogia dos homens empenhando-se na luta por sua libertação" (2001, p. 22).

D4 ainda destaca que:

Encontraríamos muito para a educação ambiental quando ele fala do sujeito. Aquele sujeito que conhece a si mesmo e reconhece o outro. Então nesse processo de conhecer ao outro está o respeito pela vida do outro e com a minha vida. Se eu respeito a minha vida, eu respeito à vida do outro, eu tenho que proteger o meio ambiente. Eu estou respeitando o meio ambiente. Então nesse sentido ele pode trazer um grande aporte à educação ambiental. 
D5 nos diz que inicialmente devemos buscar compreender como Paulo Freire entendia a sua relação com o meio ambiente. Pois Freire dizia que "gostaria de ser lembrado como alguém que amava as gentes, as plantas, os animais, a terra e os rios". E relata que no seu último ano de vida ele deixou um escrito sobre ecologia, onde parte dele foi publicada postumamente no livro Pedagogia da Indignação. Sendo assim "no final da vida, Paulo Freire estava muito sensibilizado com essa questão da ecologia".

De acordo com D6, há uma relação bastante forte e interessante, pois o pensamento de Paulo Freire está pautado na pedagogia humanizadora, ou seja, "uma pedagogia que propõe outro paradigma em termos de sistema produtivo, de relação de educação horizontais". Sendo assim:

[...] Quando a gente pensa nas questões socioambientais em termos de preservação e ampliação da vida humana e mais do que isso, uma vida humana com dignidade para todos, um planeta também que precisa ser respeitado e entendido como um organismo vivo em que estamos nele, como diz Paulo Freire, com ele. Então, vejo que é uma das possibilidades que nos faz ter esperança de que outra educação é possível, de que outra relação entre as pessoas é possível. E aí depende de nós fazermos essa opção e essa construção (D6).

Segundo D8, "não é que Paulo Freire tenha falado ou escrito sobre EA, mas muitas pessoas o utilizam para trazer os seus ensinamentos para dentro da área, para dentro do campo da EA", pois:

[...] quando a gente pensa, por exemplo, que a EA precisa ser crítica é uma das categorias que a gente encontra na vida de Paulo Freire, na obra de Paulo Freire, a questão da criticidade, o quanto que a educação precisa ser crítica. Então a gente consegue beber nos ensinamentos freireanos numa educação crítica, reflexiva, emancipatória e libertadora, e trazer isso para dentro do campo da educação ambiental. A educação ambiental precisa ser crítica, reflexiva, emancipadora.

A esse respeito, Araújo (2015, p. 36) declara que "a criticidade é condição para a emancipação dos sujeitos, para a formação de sujeitos autores de sua história de vida, capazes de identificar e problematizar questões socioambientais e agir-refletir-agir sobre elas". E Lima (2004) reitera que Paulo Freire, ao propor uma educação libertadora contribui para a educação ambiental emancipatória através da problematização de temas geradores do cotidiano dos discentes, sensibilizando-os para as questões ambientais.

D7 destaca a importância da contribuição de freiriana para a dimensão política da EA, pois para Freire, educação é um ato político. E explica que lhe incomoda atualmente a "despolitização" dessa área de conhecimento, portanto:

[...] somente a teoria freireana pode salvar esta atividade humana, que implica também a relação humana com a natureza, com seres inanimados, com seres vivos... a natureza dos que não são humanos, que não são da espécie... com o meio ambiente, vamos ser mais precisos, mais restritamente né, a tal da educação ambiental, eu acho que ela só tem salvação com a teoria freiriana (D7).

A politização das questões que envolvem a EA é abordada por Lima (2004, p. 89), onde declara: 
A despolitização do debate ambiental é outro dos motivos relevantes que estimularam a reflexão comparativa entre a educação ambiental convencional e a possibilidade de outra educação libertadora. Por um lado, refere-se a certo tratamento ingênuo dado, tanto à questão ambiental quanto à educação ambiental, que por compreendê-las como problemas ecológicos "stricto sensu" ou técnicos acaba por desconsiderar o teor político e conflitivo que está na gênese de sua emergência.

D7 afirma que "quando a dimensão política é afastada de qualquer atividade humana, essa relação deixa de ser humana. Então não faz o menor sentido a gente falar na neutralidade de qualquer relação humana", e deixa claro que a dimensão política é essencial e sustenta todo os campos de conhecimento, sobretudo a EA. Essa afirmativa corrobora com Carvalho (2006) que estabelece um "modelo" como orientação para construção e planejamento de atividades de EA, onde destaca o papel central da dimensão política para tratar tais questões, identificando mais outras duas dimensões como constituintes dessa práxis - a dimensão de conhecimentos e a de valores.

Para Layrargues (2002, p. 189), a EA “é um processo educativo eminentemente político, que visa ao desenvolvimento nos educandos de uma consciência crítica acerca das instituições, atores e fatores sociais geradores de riscos e respectivos conflitos socioambientais".

\subsection{Ações desenvolvidas que envolvam Educação Ambiental}

De acordo com os dirigentes, podemos identificar diversas ações desenvolvidas pelas Cátedras Paulo Freire que envolvem Educação Ambiental, conforme podemos observar no Quadro 1, apresentado a seguir:

Quadro 1 - Contribuições e ações desenvolvidas envolvendo Educação Ambiental.

\begin{tabular}{|l|c|c|c|c|c|c|c|c|}
\hline \multicolumn{1}{|c|}{ AÇÕES } & \multicolumn{7}{c|}{ DIRIGENTES } \\
\cline { 2 - 8 } & D1 & D2 & D3 & D4 & D5 & D6 & D7 & D8 \\
\hline $\begin{array}{l}\text { Casa da Cidadania } \\
\text { Planetária }\end{array}$ & - & - & - & - & - & X & - & - \\
\hline $\begin{array}{l}\text { Construção do Plano de } \\
\text { Desenvolvimento } \\
\text { Institucional (PDI) }\end{array}$ & - & - & $\mathrm{X}$ & $\mathrm{X}$ & - & - & - & - \\
\hline $\begin{array}{l}\text { Educação de Jovens e } \\
\text { Adultos (EJA) }\end{array}$ & - & - & $\mathrm{X}$ & $\mathrm{X}$ & - & - & - & - \\
\hline $\begin{array}{l}\text { Educação de Jovens e } \\
\text { Adultos } \\
\text { comunidades ribeirinhas) }\end{array}$ & - & $\mathrm{X}$ & - & - & - & - & - & - \\
\hline Eventos & $\mathrm{X}$ & $\mathrm{X}$ & $\mathrm{X}$ & $\mathrm{X}$ & - & - & - & - \\
\hline Formação de professores & - & $\mathrm{X}$ & - & - & - & - & - & - \\
\hline Grupo de leitura & $\mathrm{X}$ & - & - & - & - & $\mathrm{X}$ & - & $\mathrm{X}$ \\
\hline
\end{tabular}




\begin{tabular}{|l|c|c|c|c|c|c|c|c|}
\hline $\begin{array}{l}\text { Oferta de disciplina para } \\
\text { graduação }\end{array}$ & $\mathrm{X}$ & - & - & - & - & - & $\mathrm{X}$ & $\mathrm{X}$ \\
\hline Pesquisa & $\mathrm{X}$ & - & - & - & - & $\mathrm{X}$ & $\mathrm{X}$ & $\mathrm{X}$ \\
\hline Projetos de extensão & - & - & $\mathrm{X}$ & $\mathrm{X}$ & - & - & - & $\mathrm{X}$ \\
\hline $\begin{array}{l}\text { Projetos pelo } \\
\text { Observatório }\end{array}$ & - & - & $\mathrm{X}$ & - & - & - & - & - \\
\hline MoemaVieze & $\mathrm{X}$ & - & - & - & - & - & - & - \\
\hline
\end{tabular}

Fonte: Os autores.

$\mathrm{X}=$ Ação desenvolvida

Em relação às atividades desenvolvidas nas Cátedras, as entrevistadas afirmaram desenvolver ações que envolvessem EA de algum modo, seja direta ou indiretamente. Segundo D1, a Cátedra em questão desenvolve pesquisa, trabalho de editoração e eventos que divulgam esse pensamento. Já de forma mais ampla, há oferta de disciplina eletiva interinstitucional para graduação "aberta a todos os estudantes da universidade, a estudantes de graduação de outras instituições e egressos de até cinco anos". A disciplina também conta com a participação de pessoas da pós-graduação "que vêm como ouvintes ou vêm mesmo com matrícula, mas sem contar ponto", afirma.

Também é desenvolvido um grupo de leitura, "o grupo de leitura é um grupo que, de fato, também dá a sua contribuição sobre a influência ou a contribuição de Paulo Freire para a educação ambiental" (D1). Ao se referir ao grupo de leitura, D1 pontua: "lá realmente a gente tem um grupo que é plural, interprofissional, interinstitucional, então é um trabalho muito interessante". A respeito desse tipo de atividade (grupo de leitura) Santa Anna (2017, p. 40), nos explica que: "[...] A leitura está associada à manifestação da prática cidadã, constituindo um dos direitos dos indivíduos ter acesso ao livro e à leitura, por conseguinte, pautados nos princípios democráticos, caberá ao Estado e demais instituições sociais fomentar políticas, de modo a despertar a prática da leitura na sociedade".

Isso evidencia a contribuição positiva desse tipo de ação que não se limita apenas à construção de conhecimentos através da leitura. Conforme afirma Freire (2009), a leitura possibilita o desenvolvimento individual que irá ocasionar desenvolvimento e transformação no meio onde o sujeito atua.

D2, por sua vez, declarou que são realizados eventos sobre EA nos quais são desenvolvidos debates envolvendo temas como "educação popular na Amazônia, com participação de Movimentos Sociais, entre os quais o Movimento de Atingidos por Barragens, e populações das águas e das florestas".

Para Campello (2000), os eventos científicos podem desempenhar diversas funções: encontros como forma de aperfeiçoamento de trabalhos científicos, uma vez que os trabalhos apresentados mudam substancialmente após apreciação nos eventos; encontro como reflexo do estado da arte, pois os trabalhos apresentados durante o evento podem refletir o panorama da área e o perfil dos seus membros e encontros como forma de comunicação informal, pois as conversas informais com seus pares constituem parte importante dos eventos. 
Já D3 salienta "um aspecto muito importante a ser destacado é que a Cátedra Paulo Freire está vinculada ao Instituto Mercosul de Estudos Avançados, o IMEA". Outro aspecto que a dirigente ressaltou foi que a Cátedra reúne docentes que trabalham com diferentes referenciais teóricos. A mesma também nos diz que a Cátedra organizou um evento que teve como objetivo propor um debate para a construção do Plano de Desenvolvimento Institucional (PDI). Esse evento "possibilitou recuperar o projeto inicial da nossa universidade e também projetar novos horizontes. Foi um momento muito bonito, muito intenso que eu vivenciei que me permitiu entender o potencial da Cátedra Paulo Freire".

D4 nos fala sobre alguns conceitos e algumas proposições que movimentaram diferentes atividades da Cátedra desde a sua criação. Primeiramente "estávamos preocupados em que as diferentes áreas deveriam, de certa forma, assessorar, ajudar na criação e no desenvolvimento dos cursos que a universidade estava abrindo". Através dessa necessidade foi proposta a criação da Cátedra "mas não a chamamos de Cátedra de educação por que não queríamos. Então chamamos Cátedra Paulo Freire".

Após a criação da Cátedra propuseram uma série de atividades ligadas a projetos de extensão. Essas atividades, de certa forma, eram sugestões dos estudantes que tinham interesse em fazer algo com a população. Em algumas dessas atividades de extensão desenvolvidas, um grupo foi à comunidade "ajudar as pessoas a ter cuidado ambiental, a fazer educação ambiental. Simples trabalhos, mas muito significativos" (D4). Segundo Rodrigues et al (2013), ao serem desenvolvidas atividades de extensão ocorre um fortalecimento da relação universidade-sociedade, possibilitando contribuições em ambas as partes. Além disso, podem gerar também qualidade de vida aos cidadãos.

D4 ainda aborda alguns conceitos ligados à extensão como a interdisciplinaridade, integração e currículo paralelo que se relacionam entre si. Ao falar de integração, a dirigente menciona um problema que ocorreu dentro da universidade, no qual colaborou para o discurso vazio de integração: "estávamos com o discurso da integração, mas fisicamente fomos nos desintegrando". Porém, ela aponta que "a integração pouco acontece no currículo da universidade, mas no currículo paralelo é a diferença da [universidade onde está sediada]". Consequentemente, segundo D4, o currículo paralelo ocorre muito mais fora da universidade "quando um colombiano, um chileno e um peruano se juntam para fazer uma comida, para discutir a política do seu país, a economia do seu país, o sonho quando eles voltarem".

Dessa forma, todos os conceitos citados estão relacionados à interdisciplinaridade. Pois D4 afirma que, por um período, acharam que a interdisciplinaridade era apenas um discurso em que se juntavam partes "um pouquinho de geografia, com um pouquinho de história e então temos a interdisciplinaridade". Porém "A interdisciplinaridade fundamentalmente é uma atitude e um pensamento", afirma.

Para Fazenda (2015), ao definir interdisciplinaridade apenas como junção de disciplinas, pensamos apenas na formatação da sua grade ou no currículo, mas se pensarmos em atitude ousada em busca ao conhecimento, devemos levar em consideração aspectos como a cultura. Sendo assim, devemos levar em consideração a indissociabilidade da interdisciplinaridade e integração.

D5 aponta para o desenvolvimento da casa da cidadania planetária "com a ideia de que a ecologia não tem fronteiras". Também foram desenvolvidos projetos abordando a temática e pesquisas que resultaram em tese de doutorado. Ele também destaca "eu escrevi um livro sobre a pedagogia da terra, que foi pedido pelos meus alunos. São 7 lições sobre o assunto, mostrando essa dimensão socioambiental". 
D6, por sua vez, evidencia o desenvolvimento do grupo de leitura como uma das ações desenvolvidas na qual a considera "mais forte". No qual já realizaram a leitura dos livros Pedagogia do Oprimido e Pedagogia da Esperança. O Grupo de Leitura foi idealizado "para abranger e ampliar as possibilidades de participação, abranger a maior número de participantes mais diretos".

D7 declara que a Cátedra em que atua é vinculada ao programa de pós graduação em educação da instituição de ensino em que é sediada, assumindo um papel de grupo de pesquisa, onde há contribuição de diversos outros docentes que fazem pesquisas referenciadas em Paulo Freire, tanto no mestrado quanto no doutorado.

Além disso, a referida Cátedra vem oferecendo cursos e oficinas para alunos de graduação no âmbito de um projeto chamado "Escola da Ciência". O mesmo afirma que têm prioridade no projeto Escola da Ciência os alunos que desejam desenvolver projeto de iniciação científica, e que a universidade fornece para estes uma bolsa. $\mathrm{O}$ dirigente enfatiza a questão da importância de incentivar uma cultura de pesquisa também na graduação.

Segundo D8, a Cátedra que dirige é fruto do seu trabalho de pós doutoramento, onde pesquisou como a sustentabilidade está presente nos espaços freireanos. De acordo com a mesma, o espaço atualmente desenvolve uma pesquisa com financiamento institucional que seria a continuidade do seu trabalho de pós doutorado. Para além disso, a Cátedra atua na comunidade do seu entorno com projetos e cursos de extensão sobre EA, oferta de grupos de leitura sobre as obras freireanas, e ministra uma disciplina para alunos da graduação.

\section{Contribuições das ações desenvolvidas com $E A$}

A respeito das contribuições de ações desenvolvidas e sua periodicidade, D2 relata que “já foram desenvolvidas atividades de Educação de Jovens e Adultos em comunidades ribeirinhas em que questões ambientais eram tratadas". E reitera: "Atualmente questões ambientais são trabalhadas em turmas de filosofia com crianças em escolas públicas e em turmas de Educação de Jovens e Adultos em ambientes hospitalares, cuja população é oriunda do interior do estado e proveniente de comunidades ribeirinhas, quilombolas, indígenas, etc".

D2 segue afirmando que, no ambiente do Núcleo de Educação Popular Paulo Freire (NEP), além das atividades de Educação de Jovens e Adultos em comunidades ribeirinhas, são desenvolvidas atividades de formação de educadores, onde também são tratadas questões da EA na Amazônia.

Já na Cátedra, D2 informa que “estão sendo iniciadas pesquisas que tratam a educação popular em diferentes contextos educacionais, algumas em comunidades indígenas e quilombolas". E destaca:

Apesar do foco destas pesquisas não ser a educação ambiental, esta perpassa pelo debate nas pesquisas realizadas. É importante destacar que os eixos temáticos de pesquisa da Cátedra envolvem a educação popular e a educação do campo, das águas e das florestas na Amazônia, educação indígena, quilombola e movimentos sociais na Amazônia.

D2 finaliza dizendo: "por ser Paulo Freire o principal referencial do NEP e da Cátedra, a questão ambiental sempre tem destaque na discussão ético-política do viver de homens e mulheres na Amazônia, face à biodiversidade desta região". 
Em relação a essa questão, D3 salientou que há membros que desenvolvem trabalhos com a educação ambiental fomentando projetos através do Observatório Educador Ambiental Moema Vieze. Entretanto, de forma indireta, são desenvolvidas atividades como a Educação de Jovens e Adultos que, segundo ela, perpassam pela "questão da educação ambiental, uma vez que focam em questões como a conscientização, humanização. Que volto a dizer são questões tão importantes para Paulo Freire e para a EA", afirmou D3.

D4 corrobora ao ressaltar a educação de jovens e adultos como "uma educação para diminuir a opressão" D4. E salienta:

[...] Dentro da educação de adulto aparece um conceito que é importante: educar adultos não é só educar, ou só participam do processo educativo pessoas analfabetas. É uma condição que temos aí. É claro que nós estamos fazendo uma educação em geral, educação para a cidadania, educação para formar o ser, para o desenvolvimento humano. Essa era a educação de adultos que nós estávamos pensando.

Logo, "a educação de adultos corresponde ser adulto a educação para aquele que se desenvolve, e continua nesse momento com pessoa adulta" (D4). Contudo se fez necessário repensar a formação dos professores com o intuito de atingir esse objetivo. E assim "a Cátedra, de certa forma, estava pensando também com esse objetivo de educação geral, educação de adultos, formação de professores e, consequentemente, contribuir com projeto político pedagógico da universidade" (D4).

Já D5 aponta para a dimensão da sustentabilidade como uma categoria fundamental da educação do presente e do futuro. E afirma que a contribuição para a educação ambiental:

Não é só andar nas trilhas, entrar no mar, proteger as plantas, mas é, sobretudo, proteger o local de trabalho para que seja digno, para que não seja degradado, para que o ambiente escolar ou não contribua para essa visão integrada do ser humano. A gente sabe que Paulo Freire dizia que não há ensino-aprendizagem fora da procura, da boniteza e da alegria. Ressalto a boniteza, acho que tem tudo a ver com educação ambiental.

Por sua vez, D6 afirma que não tem os "focos específicos com essa temática recorrendo a autores especializados no tema, ainda". Porém, já foi procurado para uma consulta de um projeto de doutorado de um dos professores da universidade em que atua que gostaria de trabalhar com Educação Ambiental nos currículos de diferentes países do mundo e tem feito avanços nessa direção. Ele também relata que um dos participantes do grupo de pesquisa, em outra especialização, desenvolveu um trabalho com questões ligadas ao Porto, à produção de resíduos e à formação dos trabalhadores do Porto "utilizando o referencial freireano como uma possibilidade ali de busca de consciência. Consciência de si, consciência do trabalho, da luta por melhores condições, melhores relações com o ambiente". E ressalta que o grupo de pesquisa busca manter o pensamento de Paulo Freire presente, fortemente, dentro das pesquisas realizadas não só pelos membros do grupo, mas também por aqueles que gostariam de ter Paulo Freire como referencial teórico. Sendo assim, a Cátedra pode ajudar nessa aproximação. E reitera: “[...] outros alunos de outros grupos, quando vêm para atividade da Cátedra, em geral eles também vêm buscar um referencial para as pesquisas. E, em contrapartida, também enriquecem o nosso trabalho trazendo aí possibilidades".

Segundo D7, a Cátedra tem contribuído academicamente para o desenvolvimento da temática de EA. Atualmente têm duas pesquisas nessa linha, uma sobre o conceito de 
alfabetização ambiental e outra sobre a obra de Francisco Gutiérrez, que "dos freirianos, foi o que mais tratou da questão ambiental" (D7).

D8 alega que vem abordando a temática nos âmbitos da pesquisa, dos projetos de extensão e na disciplina ministrada como ação de ensino. Enfatiza que a pesquisa trata da questão da sustentabilidade nos espaços freirianos, e sobre os grupos de leitura, declara:

A primeira obra da gente lá na Cátedra foi o Pedagogia da Autonomia, no segundo grupo de leitura nós trabalhamos o Pedagogia do Oprimido, e aí compreendendo a sustentabilidade de uma maneira bem ampla, não só como ambiental. Estes grupos de leitura também favorecem a sustentabilidade porque a gente consegue trazer a pedagogia de Paulo Freire para ser discutida com pessoas de dentro da universidade e de fora da universidade.

Diante destas respostas inferimos que são várias as ações desenvolvidas com a EA nos espaços formativos que fomentam o pensamento e a pedagogia de Paulo Freire.

\section{Considerações finais}

De acordo com os dirigentes, Paulo Freire influencia trabalhos da educação ambiental. Pois, a visão de mundo e concepções de Paulo Freire também são exploradas pela educação ambiental, buscando a transformação através de atores socioambientais críticos, que possam ser autores da sua própria história.

Além disso, podemos constatar diversas ações desenvolvidas nas Cátedras Paulo Freire, Centro e Instituto, sendo elas: eventos científicos, oferta de disciplinas, pesquisas, extensão, grupos de leituras, formação de professores e atividades de educação de jovens e adultos tradicional e de comunidades ribeirinhas e quilombolas. No Instituto Paulo Freire constatamos como uma das ações desenvolvidas a casa da cidadania planetária e projetos de pesquisa. Deste modo, é inegável que estes espaços formativos representam focos de ações de pesquisa, ensino e extensão trazendo contribuições diversas a diferentes atores sociais, podendo estes ser: professores em formação inicial ou continuada, jovens e adultos em processo de alfabetização, estudantes de pós-graduação, dentre outros.

O pensamento freireano não tem fronteiras, sendo utilizado como referencial teórico pela importância do seu olhar ético-político. Tal olhar esteve sempre voltado a processos educativos, pois, para Freire, a educação é capaz de mudar pessoas e estas podem mudar o mundo. Nesta perspectiva, investir em diferentes processos educativos, como os espaços formativos aqui investigados estão fazendo, representa esperança e confiança nos seres humanos. E nós, humanos, temos a responsabilidade ética e estética de respeitar o mundo natural e o mundo social, caminhando no sentido da sustentabilidade socioambiental.

\section{Agradecimentos}

Agradecemos à Cátedra Paulo Freire - Educação para a Sustentabilidade (UFRPE) por viabilizar nossa pesquisa; à Pró-reitoria de Pesquisa e Pós Graduação da UFRPE, bem como ao $\mathrm{CNPq}$ pelo apoio financeiro; aos Dirigentes das Cátedras, Instituto e Centro Paulo Freire pela acolhida. 


\section{Referências}

Araújo, M. L. F. O quefazer da educação ambiental crítico-humanizadoranaformação inicial de professores de biologia na universidade. 2012. 240 f. Tese (Doutorado em Educação) - Programa de Pós-Graduação em Educação, Universidade Federal de Pernambuco, Recife.

Araújo, M. L. F. A educação ambiental crítico-humanizadora na formação de professores de biologia. Recife: Ed. UFPE, 2015.

Bardin, L. Análise de conteúdo. Lisboa: Edições 70, 1994.

Belei, R. A. et al. O uso de entrevista, observação e vídeo gravação em pesquisa qualitativa. Cadernos de Educação, Pelotas: UFPel, 2008. Recuperado em 15 de novembro, 2020. http://www.unisc.br/portal/upload/com_arquivo/1350501221.pdf

Brasil. Constituição da República Federativa do Brasil. Brasília, DF: Senado Federal: Centro Gráfico, 1988. 292 p. Recuperado em 10 de Junho, 2020. http://www.planalto.gov.br/ccivil 03/Constituicao/Constituicao.htm

Calado, A. J. F. Paulo Freire: sua visão de mundo, de homem e de sociedade. Caruaru: Edições Fafica, 2001.

Campello, B. S. Encontros científicos. In: Campello, B. S.; Cendòn, B. V.; \& Kremer, J. M. (ORG). Fontes de informação para pesquisadores e profissionais. Belo Horizonte: Ed. UFMG, 2000, p. 7307.

Carvalho, I. C. M. Educação ambiental: a formação do sujeito ecológico. 2. ed. São Paulo: Cortez, 2006.

Cortella, M. S. Paulo Freire: um pensamento clássico e atual. Revista e-Curriculum, São Paulo, v.7, n.3, p. 1-14, set./dez. 2001.

Dickmann, I.; \& Carneiro S. M. M. Paulo Freire e Educação ambiental: contribuições a partir da obra Pedagogia da Autonomia. R. Educ. Públ. Cuiabá, v. 21, n. 45, p. 87-102, jan./abr. 2012

Fazenda, I. C. A. Interdisciplinaridade: Didática e prática de ensino. Revista Interdisciplinaridade, São Paulo, v.1, n.6, p. 09-17, 2015.

Fraser, M. T. D.; \& Gondim, S. M. G. Da fala do outro ao texto negociado: discussões sobre a entrevista na pesquisa qualitativa. Revista Paideia, São Paulo, v. 14, n. 28, p. 140 -152, 2004.

Freire, P. Conscientização: Teoria e Prática da Libertação - Uma introdução ao pensamento de Paulo Freire. São Paulo: Moraes, 1980.

Freire, P. Educação como Prática da Liberdade. 19. ed. Rio de Janeiro: Paz e Terra, 1989.

Freire, P. Pedagogia da autonomia: saberes necessários à prática educativa. 31. ed. São Paulo: Paz e Terra, 1996. 
Freire, P. Pedagogia do oprimido. 31. ed. Rio de Janeiro: Paz e Terra, 2001.

Freire, P. A importância do ato de ler: em três artigos que se completam. 26. ed. São Paulo: Cortez, 2009.

Freire, P.; \& Faundez, A. Por uma pedagogia da pergunta. 5. ed. Rio de Janeiro: Paz e Terra, 2002.

Gil, A. C. Métodos e técnicas de pesquisa social. 6. ed. São Paulo: Atlas, 2008.

Instituto Paulo Freire. O instituto Paulo Freire: Gênese e evolução. Recuperado em 10 de Outubro de 2019. https://blog.fastformat.co/como-fazer-citacao-de-artigos-online-e-sites-da-internet/.

Jornal Utopia. Informativo do Centro Paulo Freire. Recife: n. 1, Set./Out., 2000.

Layrargues, P. P. A crise ambiental e suas implicações na educação; In: quintas, J. S. (Org). Pensando e praticando educação ambiental na gestão do meio ambiente. 2a ed. Brasília: Edições IBAMA, 2002.

Leitão, E. S. S. A prática pedagógica docente na perspectiva da humanização em Paulo Freire na EJA de Olinda. 2015. 129f. Dissertação (Mestrado em Educação) - Universidade Federal de Pernambuco, Recife, 2015.

Lima, G. F. C. Educação, Emancipação E Sustentabilidade: Em Defesa De Uma Pedagogia Libertadora Para A Educação Ambiental. In: layrargues, P. P. (coord.). Identidades da educação ambiental brasileira. Brasília: MMA, 2004. p. 87-113.

Maldonado, T. Meio ambiente e ideologia. Lisboa: Sociocultur, 1971.

Oliveira, I. A.; \& Santos T. R. L. Paulo Freire na América Latina e nos Estados Unidos: Cátedras e Grupos de Pesquisas. Revista Educação em Questão, Natal, v. 56, n. 48, p. 106-139, abr./jun. 2018.

Pieper, D. S.; Santos, T.; \& Pimentel, R. Meio ambiente e justiça ambiental: a educação ambiental como práxis social. Revista Eletrônica em Gestão, Educação e Tecnologia Ambiental REGET/UFSM, v. 5, n. 5, p. 696-704, 2012. Recuperado em 19 de Março, 2019. https://periodicos.ufsm.br/reget/article/view/4142.

Rodrigues, A. L. L. et al. Contribuições da extensão universitária na sociedade. Cadernos de Graduação - Ciências Humanas e Sociais, Aracaju, v. 1, n.16, p. 141-148, Mar. 2013.

Santa Anna, J. A Importância da leitura e as contribuições das instituições: em busca de uma sociedade leitora no brasil. Pró-Discente: Caderno de Produção Acadêmico-Científica. Programa de PósGraduação em Educação, Vitória- ES, v. 23, n. 2, p. 34-53, jul./dez. 2017.

Santiago, E.; Batista Neto, J.; \& Guedes, M. G. M. Cátedra Paulo Freire da Universidade Federal de Pernambuco: memória e atualidade tecidas a várias mãos. Anais do Colóquio Internacional Paulo $\begin{array}{llllll}\text { Freire. } & 2016 . & \text { Recuperado em } & 19 & \text { de }\end{array}$ http://coloquio.paulofreire.org.br/participacao/index.php/coloquio/ixcoloquio/paper/view/782/530.

Sato, M. Educação ambiental. São Carlos, SP: RIMA, 2003. 
Saul, A. M. Paulo Freire na atualidade: legado e reinvenção. Revista e-Curriculum. São Paulo, v.14, n.01, p. $09-34,2016$.

Saul, A. M. Relatório técnico da pesquisa o pensamento de Paulo Freire na educação brasileira: análise de sistemas públicos de ensino a partir de 1990 - período 2010 a 2012. São Paulo: PUC-SP, 2012. Recuperado em $10 \quad$ de Janeiro, 2018. https://revistas.pucsp.br/index.php/curriculum/article/viewFile/27365/19377

Schraiber, L. B. Pesquisa qualitativa em saúde: reflexões metodológicas do relato oral e produção de narrativas em estudo sobre a profissão médica. Revista de Saúde Pública, São Paulo, v. 29, n. 1, p. 63-74, 1995

Silva, P. M. A presença freireana no currículo da Escola Plural. 2015. Dissertação (Mestrado em Educação) - Pontifícia Universidade Católica de Minas Gerais, Belo Horizonte, 2015.

Torres, J. R.; \& Delizoicov, D. Fundamentos da concepção educacional de Paulo Freire na pesquisa em educação ambiental no contexto formal: 12 anos de ENPEC. In: Encontro Nacional De Pesquisa Em Ensino De Ciências, 2009, Florianópolis, Santa Catarina. Anais. 1 CD-ROOM, 2009.

Trein, E. S. A Educação Ambiental numa Perspectiva Crítica. In TV Escola - Série Salto para o Futuro. A Perspectiva Crítica e Emancipatória da Educação Ambiental. Programa 4. Secretaria de Educação à Distância. Ministério da Educação. Ano XVIII, p. 41-45, 2008.

Ventura, G.; \& Souza, I. C. F. Refletindo sobre a relação entre a natureza humana, valores capitalistas e a crise ambiental: contribuições para a promoção da Educação Ambiental Crítica. Revista eletrônica Ambiente e Educação. Rio Grande, v.15, 13-34, 2010.

\section{Sobre os Autores}

\section{MARCOS PAULO DA SILVA SANTANA}

ir ORCID: https://orcid.org/0000-0003-3820-8635

Estudante de graduação no curso de Licenciatura Plena em Ciências Biológicas na UFRPE; Membro da Cátedra Paulo Freire - Educação para a Sustentabilidade da UFRPE e Integrante do Grupo de Pesquisa em Formação e Prática Pedagógica de Professores de Ciências e Biologia (FORBIO) da UFRPE. E-mail: m.paulosantana@hotmail.com

\section{RAYANNE FERNANDA DA COSTA MELO}

III ORCID: https://orcid.org/0000-0001-9367-7085

Estudante de mestrado no Programa de Pós Graduação em Ensino das Ciências (PPGEC) da UFRPE; Graduada em Licenciatura Plena em Ciências Biológicas (2019) pela UFRPE; Membro da Cátedra Paulo Freire - Educação para a Sustentabilidade da UFRPE e Integrante do Grupo de Pesquisa em Formação e Prática Pedagógica de Professores de Ciências e Biologia (FORBIO) da UFRPE.

E-mail: rayannefernanda65@gmail.com

MONICA LOPES FOLENA ARAÚJO

III ORCID: http://orcid.org/0000-0002-0688-9782 
Professora do Departamento de Educação da UFRPE; Pós Doutora em Educação (2018) pela UFS; Doutora em Educação (2012) pela UFPE; Mestre em Ensino das Ciências (2008) pela UFRPE; Coordenadora da Cátedra Paulo Freire - Educação para a Sustentabilidade da UFRPE e Líder do Grupo de Pesquisa em Formação e Prática Pedagógica de Professores de Ciências e Biologia (FORBIO) da UFRPE.

E-mail: monica.folena@gmail.com

Submetido: 7 Ago. 2020

Aceito: 28 Ago. 2020 